\title{
Desenvolvimento inicial de cultivares de videira em Muzambinho-MG
}

Lucas Eduardo de Oliveira Aparecido ${ }^{1}$

Paulo Sergio de Souza²

Gentil Luiz Miguel Filho3

Estevan Teodoro Santana Penha ${ }^{4}$

\section{Resumo}

Objetivou-se avaliar o desenvolvimento agronômico inicial de cultivares de videira, nas condições da região do sul de Minas Gerais, no Brasil. O experimento foi conduzido no setor de Fruticultura do IFSULDEMINAS - Campus Muzambinho. Os materiais vegetativos utilizados foram mudas nuas, enxertadas sobre o porta-enxerto '1103 Paulsen' pelo método de enxertia de mesa. Os tratamentos foram oito cultivares de videira rústica (Vistis labrusca L.): Isabel (1), Concord (2), Bordô (3), Isabel precoce (4), BRS Cora (5), BRS Rúbea (6), BRS Violeta (7) e Niágara Rosada (8). 0 delineamento foi em blocos ao acaso, com três repetições e oito tratamentos, e cada parcela composta por cinco plantas, totalizando 120 plantas. Em relação ao diâmetro de enxerto e porta-enxerto, as cultivares não demonstraram diferença significativa em condições iniciais. Para as variáveis altura de plantas e massa verde, a cultivar Niágara Rosada destacou-se dentre as demais.

Palavra-chave: Viticultura. Altura de planta. Uva.

\section{1 - Introdução}

A viticultura no Brasil é uma atividade extraordinária para a sustentabilidade da pequena propriedade e nos últimos anos tem se tornado importante também na geração de empregos em grandes empreendimentos, deixando de ser um cultivo de baixa escala, passando a um cultivo de grande porte, com parreiras destinadas à produção de vinhos finos (MELLO, 2011).

Um dos pretextos para a ampliação dos parreirais nas propriedades é a busca pela alimentação saudável que a população está explorando ultimamente, motivados especialmente pelos benefícios que os derivados como o vinho, o suco e os espumantes trazem à saúde dos consumidores. Borges e Ferri (2011) relatam que o aumento do interesse do consumidor nos produtos vitícolas mostra a demanda do desenvolvimento de novas áreas e, consequentemente, o potencial vitivinícola da região.

As videiras implantadas na região são as VitislabruscaL., uvas melhoradas para ter rusticidade a doenças e pragas. E são essas labruscase seus híbridos, as uvas norte-americanas, que constituem a base da produção de vinhos e de suco, além do consumo 'in natura', representando mais de $85 \%$ do volume industrializado no país (BROETTO et al., 2011).

É através das pesquisas que surge o melhoramento, a seleção de clones e de novas cultivares, além das definições de tecnologias de manejo, especialmente para as regiões tropicais e subtropicais (CAMARGO et al., 2011). Infelizmente, em nossa localidade, essas pesquisas relacionadas à produção de uva estão em desuso, devido à cultura do café que ganhou espaço.

O Sul de Minas já foi uma região produtora de videira e hoje predomina a produção cafeeira, carecendo de diversificação dos cultivos. Certamente, a videira seria uma alternativa visando o resgate

\footnotetext{
1 IFSULDEMINAS - Campus Muzambinho, Discente da Engenharia Agronômica. Muzambinho, Minas Gerias, (BR). Iucas-aparecido@ outlook.com. (35) 91816653. Rua Virgílio Martini, 1522, Jardim Mirian, Muzambinho, Minas Gerias, CEP: 37890-000

2 IFSULDEMIMAS - Campus Muzambinho, Professor Doutor Engenheiro Agrônomo. Muzambinho, Minas Gerais, (BR). paulo.souza@muz. ifsudeminas.edu. Estrada de Muzambinho, km 35, Bairro Morro Preto, 37890-000. Muzambinho, Minas Gerais.

3 IFSULDEMINAS - Campus Muzambinho, Tecnólogo em Cafeicultura. Muzambinho, Minas Gerias, (BR).gentil.miguel@muz.ifsudeminas. edu. Estrada de Muzambinho, km 35, Bairro Morro Preto, 37890-000. Muzambinho, Minas Gerais.

${ }^{4}$ IFSULDEMINAS - Campus Muzambinho, Discente da Engenharia Agronômica. Muzambinho, Minas Gerias, (BR), estevaneafmuz@yahoo. com. Estrada de Muzambinho, km 35, Bairro Morro Preto, 37890-000. Muzambinho, Minas Gerais.
} 
de uma tradição, além de ampliar as oportunidades de culturas para os agricultores tradicionalmente de pequenas propriedades.

Como a videira é uma excelente opção para a diversificação das culturas na região e não foram encontrados trabalhos para determinação de melhores cultivares, objetivou-se determinar o desenvolvimento agronômico inicial de cultivares de videira, destinadas à produção de suco, nas condições predominantes da região do sul de Minas Gerais, no Brasil.

\section{2 - Material e Métodos}

O experimento foi conduzido no setor de Fruticultura do IFSULDEMINAS - Campus Muzambinho, localizado no município de Muzambinho, região sul do estado de Minas Gerais. A localidade do experimento foi delimitada pelas coordenadas geográficas: $21^{\circ} 20^{\prime} 59,94^{\prime \prime}$ e $46^{\circ} 31^{\prime} 34,82^{\prime \prime} \mathrm{W}$, com média de 1013 metros de altitude. De acordo com Aparecido e Souza (2014), a classificação climática predominante na região, segundo Thornthwaite (1948), é B4rB'2a, com temperaturas médias anuais variando em torno de $18^{\circ} \mathrm{C}$ e precipitação média anual de 1605 milímetros (Figura 1).

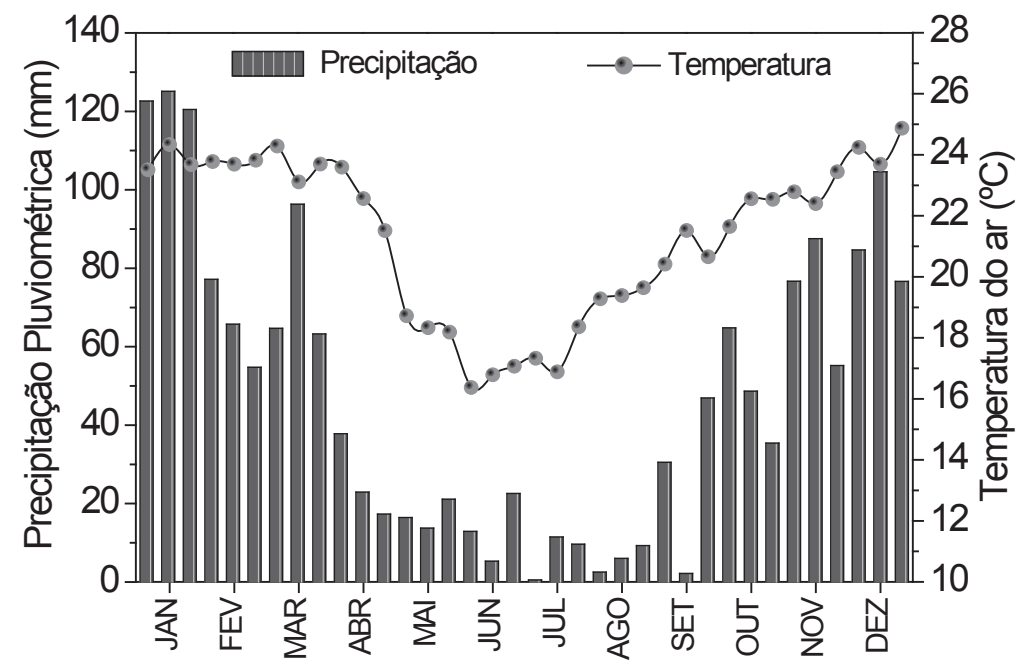

Figura 1. Variação decendial da temperatura média do ar e da precipitação pluviométrica de Muzambinho-MG (2006 a 2013).

Fonte: Elaboração dos autores.

A área experimental foi devidamente dessecada para o posterior preparo do solo (sulcagem). A implantação da cultura iniciou com marcação e alinhamento, sendo o plantio realizado pela manhã, em setembro de 2010. Retirou-se da área experimental uma amostra de solo (0 a $20 \mathrm{~cm})$ cujas características químicas iniciais determinadas foram: $\mathrm{pH}$ de 6,41 (água -1:2,5); 3,28 dag/kg de $\mathrm{MO}$; $92,2 \mathrm{mg} / \mathrm{dm} 3$ de P (Mehlich 1); $370 \mathrm{mg} / \mathrm{dm} 3$ de $\mathrm{K}$ (Mehlich 1); 6,0 cmolc/dm3 de Ca (extrator $\mathrm{KCl}$ $1 \mathrm{~mol} / \mathrm{L}$ ); $1,64 \mathrm{cmolc} / \mathrm{dm} 3$ de $\mathrm{Mg}$ (extrator $\mathrm{KCl} 1 \mathrm{~mol} / \mathrm{L}$ ); 0,0 cmolc/dm3 de $\mathrm{Al}$ (extrator $\mathrm{KCl} 1 \mathrm{~mol} / \mathrm{L}$ ); $2,89 \mathrm{cmolc} / \mathrm{dm} 3$ de $\mathrm{H}+\mathrm{Al}$ (extrator SMP).

Os materiais vegetativos utilizados foram mudas nuas, enxertadas sobre o porta-enxerto '1103 Paulsen' pelo método de enxertia de mesa. Os tratamentos foram oito cultivares de videira rústica (VistislabruscaL.): Isabel (1), Concord (2), Bordô (3), Isabel precoce (4), BRS Cora (5), BRS Rúbea (6), BRS Violeta (7) e Niágara Rosada (8).

O delineamento foi em blocos ao acaso, com três repetições e oito tratamentos, e cada parcela composta por cinco plantas, totalizando 120 plantas. 0 espaçamento utilizado foi de $2,50 \times 1,00$ metros, dispostas em seis linhas, com vinte plantas cada, em uma área de $300 \mathrm{~m} 2$. 0 sistema de condução das plantas do experimento foi na forma de espaldeira com dois fios de arame, sendo o primeiro $1,1 \mathrm{~m}$ e outro a $2,00 \mathrm{~m}$ de altura.

Antes da primeira poda, realizada no dia 28 de julho 2011 (25 cm do solo), foram mensuradas as seguintes variáveis: altura de plantas $(\mathrm{cm})$, com a utilização de uma fita métrica, sendo que a 
medição foi realizada do colo até o ápice da planta; diâmetro do enxerto e porta-enxerto (mm), aferidos $10 \mathrm{~cm}$ do solo e acima da primeira gema, respectivamente, ambos utilizando um paquímetro digital. Após a poda aferiu-se também a massa verde (g), através de uma balança analítica. Nos dias 07 de setembro 2011 e 31 de outubro de 2011, mensurou-se novamente a altura das plantas e o diâmetro do enxerto.

As pressuposições do modelo foram analisadas pelos testes de não aditividade de Tukey, teste de Bartlett e o de Shapiro Wilk, nos quais foram verificadas a aditividade dos efeitos dos modelos, homogeneidade de variância dos resíduos e a normalidade dos erros, respectivamente. Os dados foram submetidos à análise de variância, pelo teste $F$, e quando houve significância, as médias foram comparadas pelo teste de Tukey, a $5 \%$ de significância, através do software estatístico computacional "R" ( $R$ Development Core Team, 2011). Os dados foram apresentados em gráficos tipo box-plot.

\section{3 - Resultados e Discussão}

Verificou-se bom desempenho inicial das cultivares Niágara Rosada, Concord, Isabel Precoce e BRS Violeta, enquanto foi observado um desempenho intermediário das cultivares Bordô, BRS Rúbea e BRS Cora. Resultados semelhantes foram obtidos por Alvarenga et al. (2001) em estudo realizado em Lavras-MG, quando os autores obtiveram como melhor tratamento a Niágara Rosada.Em relação ao diâmetro do enxerto e porta-enxerto, todas as cultivares não apresentaram diferença significativa ao nível de 5\% de significância (Figura 2.C e D).
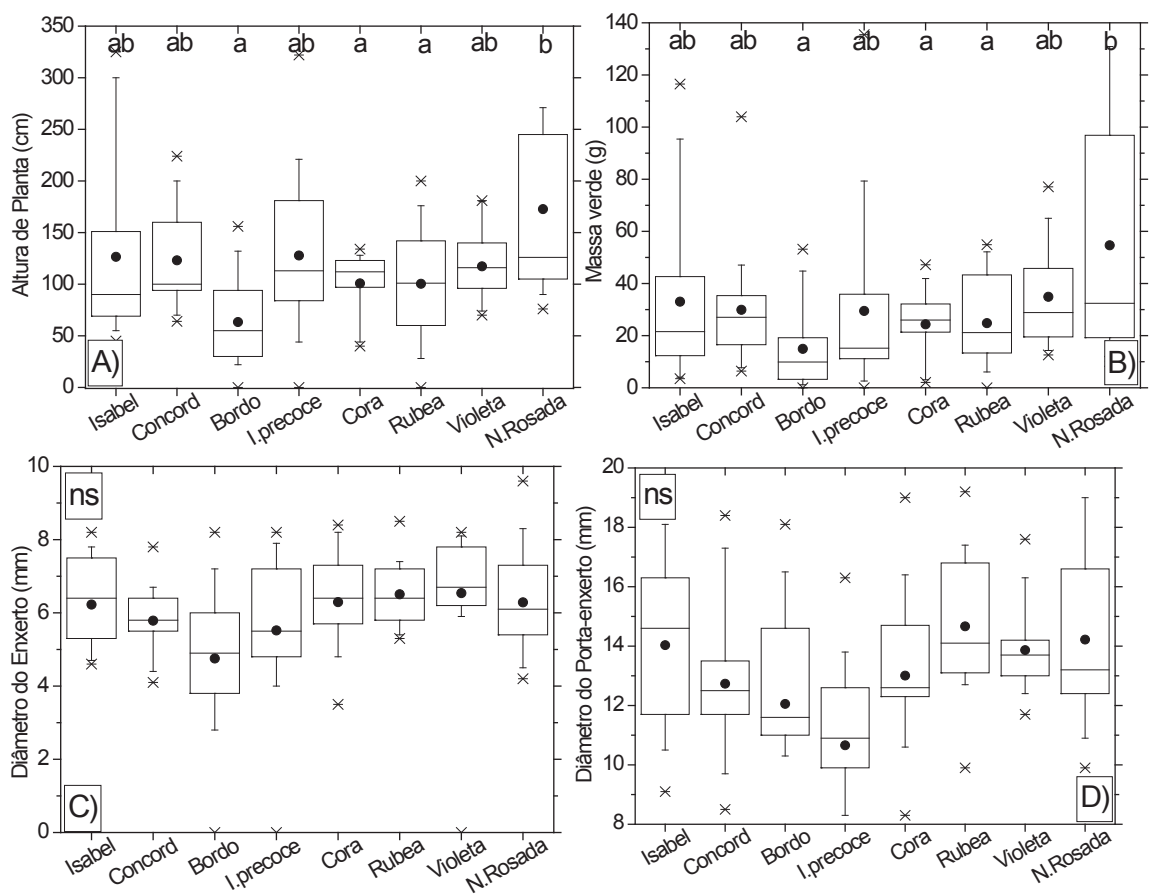

Figura 2. Variação da altura das plantas (A), massa verde (B), diâmetro do enxerto (C) e porta-enxerto (D) na videira na primeira avaliação (28 de julho 2011). Tukey ao nível de 5\% de probabilidade (ns= não significativo).

Fonte: Elaboração dos autores.

Em todos os parâmetros avaliados, as cultivares Isabel, Concord, Isabel Precoce e BRS Violeta não apresentaram diferenças significativas no desenvolvimento inicial (Figura 2).

Na segunda avaliação, concretizada no dia 07 de setembro de 2011, constatou-se que nenhuma das cultivares desenvolveu uma altura acima do primeiro arame, situado a 1 metro do colo das plantas (Figura 3.A). 

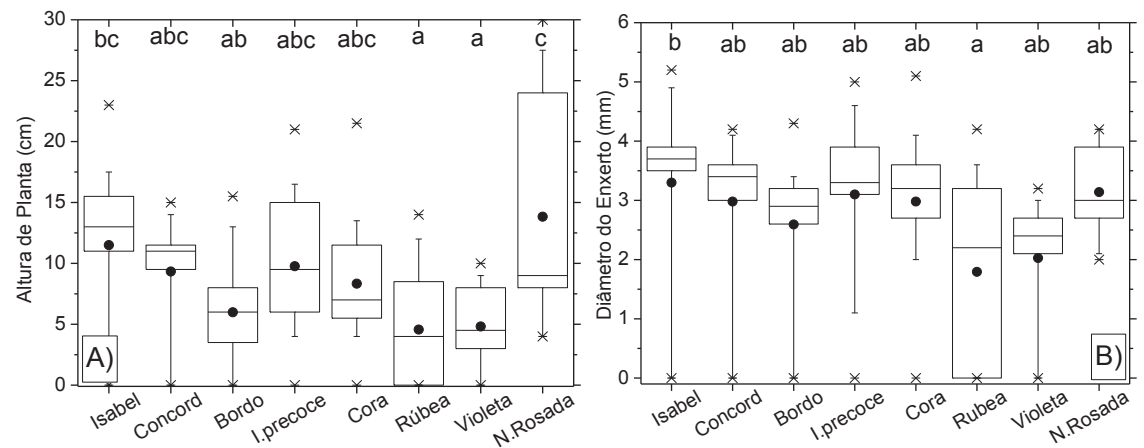

Figura 3. Variação da altura das plantas (A) e do diâmetro do enxerto (B) na segunda avaliação (07 de setembro de 2011).

Tukey ao nível de $5 \%$ de probabilidade.

Fonte: Elaboração dos autores

Em relação à altura de plantas, a cultivar Niágara Rosada destacou-se significativamente em relação à BRS Rúbea e à BRS Violeta, que foram as cultivares de desenvolvimento inferior (Figura 3.A).

Em relação ao diâmetro do enxerto (Figura 3.B), nota-se resultados semelhantes à primeira avaliação (28 de julho 2011), porém, a cultivar BRS Rúbea manifesta um menor desenvolvimento do diâmetro do enxerto, diferenciando da Isabel, cultivar que apresentou diâmetros médios próximos de 3,5 mm. As demais não apresentaram diferenças significativas.

Na última avaliação, realizada no dia 31 de outubro de 2011, a cultivar Niágara rosada apresentou em média $175 \mathrm{~cm}$ de altura de planta (Figura 4.A), diferenciando significativamente das demais cultivares. A menor altura de plantas foi observada na cultivar BRS Cora, com $80 \mathrm{~cm}$
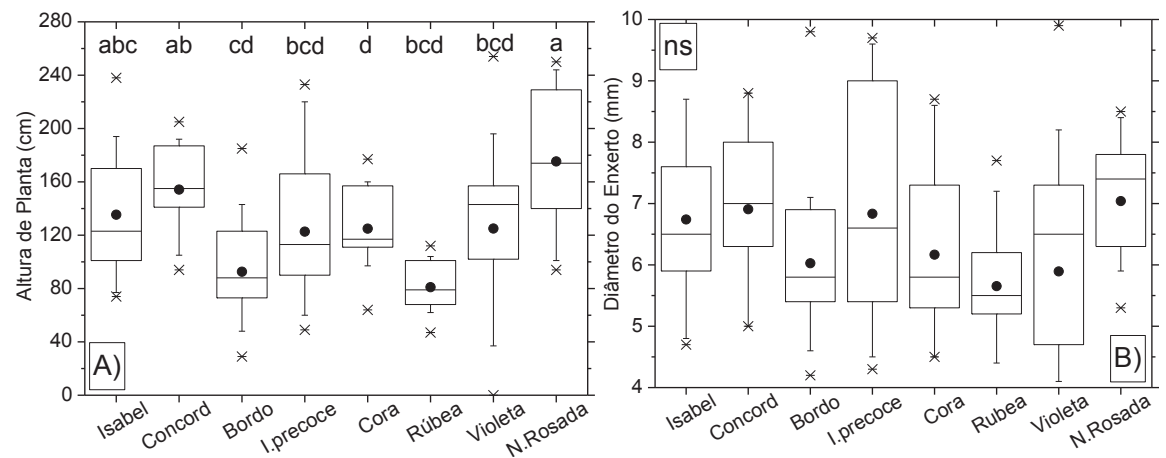

Figura 4. Variação da altura de plantas (A) e do diâmetro do enxerto (B) na terceira avaliação (31 de outubro de 2011).

Tukey ao nível de $5 \%$ de probabilidade(ns= não significativo).

Fonte: Elaboração dos autores.

4.B).

Novamente não houve diferença significativa em relação ao diâmetro do enxerto (Figura

Em trabalho semelhante, realizado nas condições predominantes de Lavras-MG, com as mesmas cultivares de videira, os pesquisadores Dias et al., (2011) também observaram que a cultivar Niágara Rosada apresentou um bom desenvolvimento inicial.

\section{4 - Conclusões}

Nas condições predominantes do município de Muzambinho, a cultivar Niágara Rosada apresenta o melhor desenvolvimento agronômico inicial, enquanto as cultivares BRS Rúbea e BRS Cora, os menores. 


\section{Initial development of agronomic grapevine cultivars in $\mathrm{Mu}$ - zambinho - MG}

\section{Abstract}

This study aimed to evaluate the initial development of agronomic grapevine cultivars, the conditions of the southern region of Minas Gerais, Brazil. The experiment was conducted at the Fruit sector IFSULDEMINAS - Campus Muzambinho. The plant materials used were naked seedlings, grafted on rootstock '1103 Paulsen' method of bench grafting. Treatments were eight rustic grape cultivars (Vistis labrusca L.): Isabel (1), Concord (2), Bordo (3), Isabel Precoce (4) BRS Cora (5), BRS Rúbea (6), BRS Violeta (7) and Niagara Rosada (8). The design was a randomized block design with three replications and eight treatments, each plot consisting of five plants totaling 120 plants. Regarding the diameter of the graft and rootstock cultivars showed no significant difference in initial conditions. For the variables plant height and fresh weight, to cultivate Niagara Rosada stood out among the others.

Key words: Viticulture. Plant height.Grape.

\section{Referências Bibliográficas}

ALVARENGA, A. A. Avaliação de cultivares porta-enxertos e produtoras de videira (Vitisspp.) em condições de solos ácidos e alumínio. 2001.153p. Tese (Doutorado em Agronomia) - Universidade Federal de Lavras, Lavras.

APARECIDO, L. E. O.; SOUZA, P. S. Boletim Climático Nº10 - Janeiro/2014. Disponível em: http://www.muz.ifsuldeminas.edu.br/images/stories/PDF/2014/boletim_2014/Boletim_Clima_JANEI_ 14.pdf. Acesso em: 19 fev.2014.

BORGES, M; FERRI, V. C. Método de elaboração e rentabilidade econômica do suco de uva. 2011. 5p. TCC (Especialização em Ciência dos Alimentos) - Universidade Federal de Pelotas, Pelotas.

BROETTO, D.et al. Desenvolvimento e ocorrência de pérola-da-terra em videiras rústicas e finas enxertadas sobre os porta-enxertos 'VR 043-43' e 'Paulsen 1103'. Revista Brasileira de Fruticultura, Jaboticabal - SP, Volume Especial, E. 404-410, Outubro 2011.

CAMARGO, U. A. et al. Progressos na viticultura brasileira. Revista Brasileira de Fruticultura, Jaboticabal, vol.33, n.1, p. 144-149. 2011.

DIAS, F. A. N. et al. Desempenho agronômico inicial de diferentes cultivares de videira para produção de suco em Minas Gerais Brasil. In: XIII CONGRESSO LATINOAMERICANO DE VITICULTURA Y ENOLOGÍA, 2011, Santiago-Chile. Anais... Santiago:[s.n.], 2011.

MELLO, L. M. R. Vitivinicultura brasileira: panorama 2010. Disponível em:<http://www.cnpuv.embrapa. br/publica/artigos/prodvit2010.pdf>. Acessoem: 17 mar. 2012.

R DEVELOPMENT CORE TEAM. R: A language and environment for statistical computing. Vienna, Austria:R Foundation for Statistical Computing, 2011. ISBN 3-900051-07-0, URL:http://www.R-project. org.

THORNTHWAITE, C. W. An approach towards a rational classification of climate.Geographical Review, London, v.38, n.1, p.55-94, 1948. Disponívelem: <http://www.unc.edu/courses/2007fall/geog/801/001/ www/ET/Thornthwaite48-GeogrRev.pdf > .Acesso em: 12 jan.2014.

Histórico editorial

Recebido: 03/01/2013

Avaliação e copidesque: 03/01/2013 a 10/02/2014 